\title{
Attitude and Practice of Aesthetic Surgery among Plastic Surgeons in Nigeria
}

Ugochukwu Uzodimma Nnadozie ${ }^{1,7}$, Charles Chidiebele Maduba ${ }^{1}$, Chukwuma David Umeokonkwo ${ }^{2}$, Christian Chidebe Anikwe ${ }^{4}$, Kingsley Okechukwu Opara ${ }^{3}$, Markson Chimaobi Isiguzo ${ }^{5}$, Victor Ifeanyichukwu Modekwe ${ }^{6}$, Ezekiel Uche Nwankwo ${ }^{6}$, Chinedu Henry Ekwedigwe ${ }^{7} \&$ Njoku Isaac Omoke $^{7}$

${ }^{1}$ Division of Plastic Surgery, Department of Surgery, Alex Ekwueme Federal University Teaching Hospital, Abakaliki, Ebonyi State, Nigeria

${ }^{2}$ Department of Community Medicine, Alex Ekwueme Federal University Teaching Hospital Abakaliki, Ebonyi State, Nigeria

${ }^{3}$ Department of Obstetrics and Gynecology, Alex Ekwueme Federal University Teaching Hospital Abakaliki, Ebonyi State, Nigeria

${ }^{4}$ Plastic Surgery Division, Department of Surgery, Imo State University, Nigeria

${ }^{5}$ Plastic and Reconstructive Surgery Unit, Department of Surgery, Federal Medical Center, Owerri, Imo State, Nigeria

${ }^{6}$ Department of Surgery, Nnamdi Azikiwe University Teaching Hospital Nnewi, Anambra State, Nigeria

${ }^{7}$ Department of Surgery, Ebonyi State University, Abakaliki, Nigeria

Correspondence: Ugochukwu U Nnadozie, Division of Plastic Surgery,Department of Surgery, Alex Ekwueme Federal University Teaching Hospital, Abakaliki. Ebonyi State, Nigeria. Tel: 234-703-617-4165. E-mail ugodozie@yahoo.ca

Received: August 6, $2020 \quad$ Accepted: October 12, $2020 \quad$ Online Published: October 24, 2020

doi:10.5539/gjhs.v12n13p9 URL: https://doi.org/10.5539/gjhs.v12n13p9

\begin{abstract}
Background: Aesthetic surgery in developed countries is growing at an exponential rate. There is an increasing demand for cosmetic procedures in Nigeria but still, the practice is at a slow pace. Significant clients from Nigeria seek for these procedures outside Nigeria.
\end{abstract}

Objective: This study aimed at determining the attitude and practice of aesthetic surgery among plastic surgeons in Nigeria.

Method: We conducted a cross-sectional study among the attendees of the annual conference of the National Association of Plastic Reconstructive and Aesthetic Surgeons held at Calabar, Nigeria, using a questionnaire on consented participants.

Results: A total of 73 out of 84 Plastic surgeons participated in the study with a response rate of $86.9 \%$. The mean age of the respondents was $45.4 \pm 7.2$ years. Only $14(19.2 \%)$ had undergone extra training in cosmetic surgery. Most respondents 53.4\% prefer Nigerian over foreign hospitals for cosmetic surgery for various reasons. Poor awareness (42.5\%) and religious beliefs (42.5\%) contributed most to the poor acceptability of cosmetic surgery in Nigeria. The vast majority $(97 \%)$ of Nigerian plastic surgeons want the public to be engaged in awareness sensitization on cosmetic surgery and their preferred mode of sensitization was through internet / social media $(80.8 \%)$, television $(74 \%)$, and radio $(65.8 \%)$. Scar revision $(78.1 \%)$ abdominoplasty $(69.9 \%)$ and breast reduction (67.1) were the common cosmetic procedures performed by Nigerian plastic surgeons.

Conclusion: The attitude of Plastic surgeons in Nigeria to cosmetic surgery is influenced by the low acceptance of cosmetic surgery procedures by Nigerians. Attitudinal change programs, especially through social and other mass media, are desired to increase awareness and acceptance of cosmetic surgery in Nigeria.

Keywords: Attitude and Practice of aesthetic surgery; Attitudinal change; Aesthetic Surgery; Nigeria

\section{Introduction}

Aesthetic surgery, also known as cosmetic surgery is a subspecialty of plastic surgery which is concerned with the 
preservation, restoration, and enhancement of the body form (Morait et al., 2019). It is a major role of the plastic surgery specialty. Aesthetic surgery improves the psychological well-being of the client (Bradbury \& Habel, 2009). It has been shown to increase emotional stability, increase the quality of life, improve general life satisfaction, and depressed patients have shown significant improvements after aesthetic surgery (Nnadozie et al., 2020; Papadopulos et al., 2019).

This branch of plastic surgery has shown a tremendous increase in the United States with a record $299 \%$ increase between 1997 and 2003 (Sarwer et al., 2005). In this period, liposuction was the leading procedure. More recently in the US, over 1.4 million cases of aesthetic surgeries were performed in 2019 of which breast augmentation was the most common aesthetic surgical procedure(American Society of Plastic Surgeons, 2019a).

World over there has been a significant increase in the volume of aesthetic procedures done in the last decade (Swami et al., 2009). In Nigeria however, the practice of aesthetic surgery is slow-growing and not at its best yet. Three major factors have been known to influence the practice and patronage of aesthetic surgery which are the medical advancement/facility, patient characteristics, and media influences (Morait et al., 2019). In Nigeria, media influence though positive, can also be negative due to a few deaths of highly placed individuals, following aesthetic procedures (Agbo, 2018). Some other models and artists have given a media boost to cosmetic surgery. The number of specialists practicing in this subspecialty is still low compared to the minimum required by the country. This scarcity of aesthetic surgeons and the increasing demand for aesthetic surgery may have made it possible for non-professionals to practice aesthetic surgery in Nigeria with the resultant poor outcomes. It is, therefore, necessary to discover the factors that have negatively hampered plastic surgeons' interest in further specializing in aesthetic surgery, as well as finding out why those who are so trained are having limited aesthetic surgery practice in Nigeria. This is necessary because Nigeria unlike the developed countries does not have an association of aesthetic surgeons or a council to regulate the practice of cosmetic surgery in the country, and provide updates on her practice challenges. A case has been made for the increase in the number of aesthetic surgeons in Nigeria (Olawoye, 2019). Different models of achieving this including the traditional fellowship and the post-fellowship sandwich models have been suggested (Ibrahim, 2014).

More so, the number of plastic surgeons practicing in the country is grossly insufficient to handle the reconstructive burdens of the citizenry. A nation of over 193 million citizens being cared for by just 124 plastic surgeon at a ratio of about 1 plastic surgeon to about 1.5 million persons, is grossly inadequate (Nigerian Bureau of Statistics, 2017). This is far detached from the recommendation of the British Association of Plastic, Reconstructive, and Aesthetic Surgeon of 1 plastic surgeon to 100,000 population (Freshwater, 2016). This reconstructive burden may contribute to the cold attitude of the plastic surgeons toward aesthetic sub-specialization.

We, therefore, examined the attitude, and practice of aesthetic surgery among plastic surgeons in Nigeria and their desire to establish an association for aesthetic surgeons in Nigeria. Our aim is to determine the factors that are responsible for the slow pace of development of this very trendy arm of surgery in a country with well over a hundred fully certified plastic surgeons, well-developed media and movie industries as well as a significant number of clients seeking cosmetic surgical care in other countries of the world.

\section{Materials and Methods}

The practice of cosmetic surgery in Nigeria is evolving. It is emerging from the plastic, burns, and reconstructive subspecialty in Nigeria. There are 124 registered consultant plastic surgeons in Nigeria and 48 registered associate fellows in training. They all belong to the Nigerian Burns Injury Society (NBIS) and Nigerian Association of Plastic, Reconstructive, and Aesthetic Surgeons (NAPRAS). The members hold an annual scientific conference to discuss the progress in the practice of plastic surgery in Nigeria and proffer solutions to the practice. The meeting also serves as training opportunities for younger practitioners in training. Cosmetic surgery is practiced in Nigeria in tertiary, specialist, and general hospitals both privately and publicly owned. The distribution of the specialists is skewed towards the urban against the rural areas. In Nigeria, there are about three private hospitals and fifteen public teaching hospitals that are known to practice plastic surgery but non is dedicated to aesthetic surgery alone.

We conducted a cross-sectional study among the attendees of the 2019 NAPRAS/NBIS Conference at Calabar Nigeria from 26th to 31st August 2019. We did a total population survey of all the 84 specialists (both fellows and associate fellows) present at the meeting using a self-administered questionnaire. The questionnaire had three sections; the first section captured information on the socio-demographic characteristics of the participants; the second section captured information on the perspective of the respondents on the practice of cosmetic surgery in Nigeria; and the third section captured information on the types of procedures, frequency, and opinion on the challenges of the practice in Nigeria. 
We presented the socio-demographic characteristics of the respondents in frequencies and proportions. We also estimated the frequency of each of the common cosmetic surgical procedures performed by the participants using Epi Info version 7.2.3, US CDC. This study was approved by the Ethics and Research committee of Alex Ekwueme Federal University Teaching Hospital Abakaliki, Ebonyi State, Nigeria. The participants all gave written informed consent to participate in the study.

\section{Results}

A total of 73 respondents participated in the study with a response rate of $86.9 \%$. The mean age of the respondents was $45.4 \pm 7.2$ years (ranging from 27 to 62 years). The modal age group was $45-54$ years (43.3\%). The majority of the respondents were males $(\mathrm{n}=63,86.3 \%)$, married $(90.4 \%)$, consultant cadre $(79.2 \%)$ and practice in urban area $(75.43 \%)$. Only $14(19.2 \%)$ had undergone extra training in cosmetic surgery (Table 1$)$. The respondents had practiced as surgeons for $10.8 \pm 5.1$ years and have practiced as a plastic surgeon for a mean duration of $7.8 \pm 5.7$ years.

Table 1. Socio-demographic characteristics of respondents

\begin{tabular}{|c|c|c|}
\hline Variable & Frequency & Percentage \\
\hline \multicolumn{3}{|l|}{ Age (years) ${ }^{x}$} \\
\hline $24-34$ & 5 & 7.5 \\
\hline $35-44$ & 25 & 37.3 \\
\hline $45-54$ & 29 & 43.3 \\
\hline $55-64$ & 8 & 11.9 \\
\hline \multicolumn{3}{|l|}{ Sex } \\
\hline Female & 10 & 13.7 \\
\hline Male & 63 & 86.3 \\
\hline \multicolumn{3}{|l|}{ Marital status } \\
\hline Married & 66 & 90.4 \\
\hline Single & 5 & 6.9 \\
\hline Separated & 2 & 2.7 \\
\hline \multicolumn{3}{|l|}{ Religion } \\
\hline Christianity & 59 & 80.8 \\
\hline Moslem & 13 & 17.8 \\
\hline Traditional & 1 & 1.4 \\
\hline \multicolumn{3}{|l|}{ Cadre } \\
\hline Residents & 16 & 21.9 \\
\hline Consultant & 57 & 78.1 \\
\hline \multicolumn{3}{|c|}{ Had extra training in cosmetic surgery } \\
\hline Yes & 14 & 19.2 \\
\hline No & 59 & 80.8 \\
\hline \multicolumn{3}{|c|}{ Region of practice } \\
\hline South West & 23 & 31.5 \\
\hline South South & 15 & 20.5 \\
\hline South East & 19 & 26.0 \\
\hline North Central & 8 & 11.0 \\
\hline North West & 5 & 6.9 \\
\hline North East & 3 & 4.1 \\
\hline
\end{tabular}




\begin{tabular}{llc}
\hline Place of practice & & \\
Urban & 55 & 75.3 \\
Semi urban & 15 & 20.6 \\
Rural & 3 & 4.1 \\
\hline Hospital type & 43 & 58.9 \\
Teaching & 17 & 23.3 \\
Specialist & 6 & 8.2 \\
General & 5 & 6.9 \\
Others & 5 & 2.7 \\
Private & 2 & \\
\hline
\end{tabular}

$\mathrm{x}=$ Some respondents omitted their ages in the questionnaire.

The respondents (53.4\%) prefer Nigerian hospitals over hospitals outside Nigeria for cosmetic surgery. Similarly, the majority $(65.7 \%)$ of the respondents believe that there is no difference in complication rate of cosmetic surgery procedures performed in Nigeria compared to those performed outside Nigeria. Among the reasons the complications of cosmetic surgery done in Nigeria may differ from those done outside Nigeria, include lack of facilies (43.8\%), lack of expertise (32.9\%) and lack of institutional support (24.7\%, Table 2) Similarly, most of the respondents were of the opinion that the outcome of the surgery will be the same irrespective of whether the procedure is performed in Nigeria or outside Nigeria. Though $84 \%$ of the participants believed that cosmetic surgery should not be performed by just any interested doctor, only $60.3 \%$ said it should be reserved for Aesthetic/cosmetic surgeons alone. Fifty-one (70.8\%) of the respondents want the establishment of the Cosmetic Surgeons Association of Nigeria.

Table 2. Respondent's view of the practice of cosmetic surgery in Nigeria

\begin{tabular}{|c|c|c|}
\hline Variable & Frequency & Percentage \\
\hline \multicolumn{3}{|c|}{ Chose Nigerian facility over foreign for cosmetic surgery } \\
\hline Yes & 39 & 53.4 \\
\hline No & 24 & 32.9 \\
\hline Not sure & 10 & 13.7 \\
\hline \multicolumn{3}{|c|}{ Complication in Nigeria differ from those in foreign hospital } \\
\hline Yes & 18 & 24.7 \\
\hline No & 48 & 65.7 \\
\hline Not sure & 7 & 9.6 \\
\hline \multicolumn{3}{|c|}{ Is the outcome of cosmetic surgery in Nigeria likely to differ compared to abroad } \\
\hline Yes & 42 & 57.5 \\
\hline No & 26 & 35.6 \\
\hline Not sure & 5 & 6.9 \\
\hline \multicolumn{3}{|c|}{ Who should perform cosmetic surgery* } \\
\hline Aesthetic / cosmetic surgeons & 44 & 60.3 \\
\hline Obstetrician \& Gynaecologists & 11 & 15.1 \\
\hline Dermatologist & 6 & 8.2 \\
\hline Maxillofacial surgeon & 6 & 8.2 \\
\hline Ophthalmologist & 4 & 5.5 \\
\hline Orthopaedic surgeon & 4 & 5.5 \\
\hline Paediatric surgeon & 3 & 4.1 \\
\hline ENT Surgeon & 2 & 2.7 \\
\hline General Surgeon & 1 & 1.4 \\
\hline
\end{tabular}




\begin{tabular}{lll}
\hline Any surgeon interested should perform cosmetic surgery & & 8.7 \\
Yes & 6 & 84.0 \\
No & 58 & 7.3 \\
Indifferent & 5 & 68.2 \\
\hline Cosmetic surgery should be done by cosmetic surgeons alone & 45 & 22.7 \\
Yes & 15 & 9.1 \\
No & 6 & 52.1 \\
Indifferent & & 37 \\
\hline Cosmetic surgeons should be certified before performing cosmetic surgeries & 26 \\
Yes & 8 \\
No & 36.6 \\
Indifferent & 26 \\
\hline *multiple answers allowed & 11.3
\end{tabular}

*multiple answers allowed.

They also reported that cosmetic surgery was socially acceptable (56.4\%). It was reported to be more acceptable among the upper social class $(88.4 \%)$ and urban areas $(95.8 \%$, Table 3$)$. Among the factors perceived to be contributory to the less than optimum social acceptability of cosmetic surgery in Nigeria included poor awareness $(42.5 \%)$, religious beliefs (42.5\%), and level of exposure (37.0\%, Table 3$)$. About $97 \%$ of the respondents were of the opinion that there is need to engage the public on awareness sensitization on cosmetic surgery, and their preferred mode sensitization was through internet / social media $(80.8 \%)$, television $(74 \%)$, and radio (65.8\%).

Table 3. Awareness and acceptability of cosmetic surgery

\begin{tabular}{|c|c|c|}
\hline Variable & Frequency & Percentage \% \\
\hline \multicolumn{3}{|c|}{ Social acceptability of cosmetic surgery* } \\
\hline Yes & 40 & 56.4 \\
\hline No & 24 & 33.8 \\
\hline Not sure & 7 & 9.9 \\
\hline \multicolumn{3}{|c|}{ Region with better acceptability* } \\
\hline Urban & 68 & 95.8 \\
\hline Rural & 3 & 4.2 \\
\hline \multicolumn{3}{|c|}{ Social acceptability by socioeconomic class* } \\
\hline Upper class & 61 & 88.4 \\
\hline Middle class & 8 & 11.6 \\
\hline \multicolumn{3}{|l|}{ Level of acceptability* } \\
\hline Widely acceptable & 2 & 5.1 \\
\hline Averagely acceptable & 27 & 69.2 \\
\hline Poorly acceptable & 8 & 20.5 \\
\hline Not acceptable & 2 & 5.1 \\
\hline \multicolumn{3}{|c|}{ Factors that negatively affects cosmetic surgery acceptability** } \\
\hline Poor awareness & 31 & 42.5 \\
\hline Religion / Belief & 31 & 42.5 \\
\hline Exposure & 27 & 37.0 \\
\hline Societal taboos & 26 & 35.6 \\
\hline Environment & 21 & 28.8 \\
\hline
\end{tabular}




\begin{tabular}{|c|c|c|}
\hline \multicolumn{3}{|c|}{ Knew a taboo against cosmetic surgery* } \\
\hline Yes & 16 & 22.9 \\
\hline No & 54 & 77.1 \\
\hline \multicolumn{3}{|l|}{ Taboos $(n=16)$} \\
\hline Against religious belief & 10 & 62.4 \\
\hline Altering God's will & 5 & 31.3 \\
\hline Against social norm & 1 & 6.3 \\
\hline \multicolumn{3}{|c|}{ Need for more awareness on cosmetic surgery* } \\
\hline Yes & 69 & 97.2 \\
\hline No & 2 & 2.8 \\
\hline \multicolumn{3}{|c|}{ Suggested means of delivering awareness messages** } \\
\hline Internet / social media & 59 & 80.8 \\
\hline Television & 54 & 74.0 \\
\hline Radio & 48 & 65.8 \\
\hline Health education & 45 & 61.6 \\
\hline Print media & 32 & 43.8 \\
\hline Schools & 22 & 30.1 \\
\hline Town criers & 11 & 15.1 \\
\hline
\end{tabular}

*Some respondents did not respond to some questions, the valid frequencies were used for the percentage: **multiple answers allowed

Scar revision (78.1\%), abdominoplasty (69.9\%), and breast reduction (67.1) were the most common cosmetic procedures performed by the respondents (Table 4$)$.

Table 4. Common cosmetic procedures performed by respondents

\begin{tabular}{lll}
\hline Variable & Frequency & Percentage \\
\hline Have you performed any of the following procedures (multiple answers allowed) & & 78.1 \\
Scar revision & 57 & 69.9 \\
Abdominoplasty & 51 & 67.1 \\
Breast reduction & 49 & 41.1 \\
Liposuction & 30 & 39.7 \\
Mastopexy & 29 & 39.7 \\
Tattoos & 29 & 31.1 \\
Vaginoplasty & 23 & 30.1 \\
Cheiloplasty & 22 & 24.7 \\
Breast augmentation & 18 & 20.6 \\
Fat transfer & 15 & 20.6 \\
Rhinoplasty & 15 & 19.2 \\
Otoplasty & 14 & 17.8 \\
Arm-plasty /lift & 13 & 15.1 \\
Clitoroplasty & 11 & 11.0 \\
Thigh-lift & 8 & \\
\hline
\end{tabular}




\begin{tabular}{lll} 
Botox injection & 7 & 9.6 \\
Blepharoplasty & 6 & 8.2 \\
Buttock enhancement & 6 & 8.2 \\
Face-lift & 6 & 8.2 \\
Hair transplant & 6 & 8.2 \\
Genioplasty & 3 & 4.1 \\
Blow-lift & 3 & 4.1 \\
Filers & 2 & 2.7 \\
Penile resizing & 2 & 2.7 \\
Post bariatric surgical reconstruction & 2 & 2.7 \\
Dermabrasion & 1 & 1.4 \\
\hline
\end{tabular}

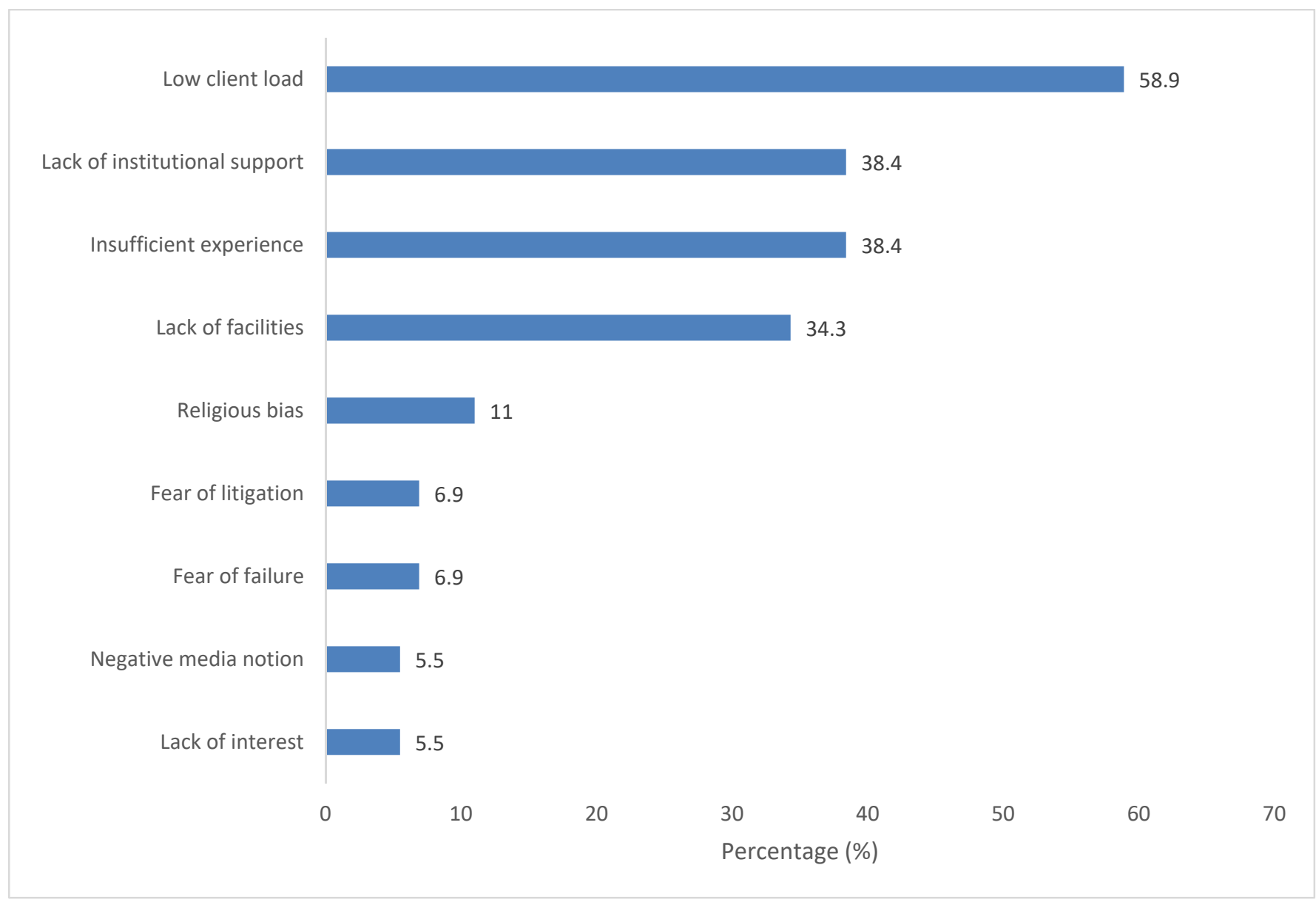

Figure 1. Factors affecting frequency of cosmetic procedure

Participants reported that the most common challenges they face were limited client load (58.9\%), insufficient experience (38.4\%), and lack of institutional support (38.4\%) (Figure 1).

\section{Discussion}

There is an increasing body image consciousness globally with cosmetic procedures becoming household words (Sarwer et al., 2005; Swami et al., 2009). In Nigeria however, there is slow pace of increase in the volume of cosmetic procedures. Some factors have been studied to determine their effect on the perceived slow progress of cosmetic surgery in the country. It has been found that university students and healthcare workers, both have high level of awareness of cosmetic procedures (Abubakar et al., 2016; Adedeji et al., 2014). It is also known that 
factors such as level of enlightenment, religious belief, social taboos, financial capacity among others, determine the demand for cosmetic surgery (Abubakar et al., 2016; Adedeji et al., 2014; Morait et al., 2019). This is in keeping also with our findings. It remains to determine the plastic surgeon's elements in their practice of cosmetic surgery.

We found a male preponderance among the plastic surgeons and a mean duration of 8 years of practice as plastic surgeons. This shows the relatively young nature of the practice in the country. This should be an advantage since specialization and fellowship training are preferable at a young age (Blasier, 2009). Despite this obvious advantage, we do not have a surging interest in cosmetic surgery in our environment. This cold attitude to cosmetic surgery among plastic surgeons in Nigeria calls for a keen assessment.

We observed that the plastic surgeons in Nigeria were more likely to choose a facility in Nigeria for aesthetic surgery showing a strong belief in the nation's hospital system. They also believe that there is no difference in complications for procedures done in Nigeria compared to those done outside Nigeria. These believes should contribute positively to their developing interest in cosmetic surgery. It is also noteworthy that plastic surgeons have concerns about the institutional support for setting up cosmetic surgery practice. This might have informed the perception that the outcome of cosmetic procedures in the country will differ with ones performed abroad. There is a perception among the plastic surgeons that the facilities in Nigeria are not good enough for the practice of satisfactory cosmetic surgery. What then is the reason why some clients would prefer a Nigerian facility to those abroad? Could it be the perceived cost profile or sheer patriotism? This remains to be unraveled in further studies.

In addition, the plastic surgeons also perceived that the effect of the taboo system, religious belief, social status, and environment of the patients bear on their acceptance of cosmetic procedures. Could these have rubbed on their willingness to pursue a further hands-on experience in aesthetic surgery? This is especially important when over $50 \%$ of the plastic surgeons see the need for more training and certification beyond a plastic surgery fellowship before one should practice cosmetic surgery.

Scar revision is the commonest procedure performed by the respondents followed by abdominoplasty, breast reduction, liposuction, and mastopexy completing the top five. This is in keeping with an earlier report in southeast Nigeria which reported that scar revision was the most common aesthetic procedure performed (Onah et al., 2010). However, the finding is different from the pattern reported in US (American Society of Plastic Surgeons, 2019a) and Brazil (Olawoye, 2019) where breast augmentation ranked the highest. The failure of the Nigerian experience to show a new trend in procedure pattern points to the fact that either new demands have not been made by clients or that the surgeons did not acquire further training in new areas or both (American Society of Plastic Surgeons, 2019a, 2019b; Sarwer et al., 2005). In another survey by Hildago et al among active American Society of Plastic Surgeons membership, over $51 \%$ of the respondents perform more than 50 primary breast augmentations per year (Hidalgo \& Sinno, 2016). This translates to an average of one case per week. This is far from being so in Nigeria. We observed low client load, poor institutional (government) support, insufficient experience on the side of the plastic surgeons, and lack of facilities among others as the leading factors responsible for the low volume of cosmetic surgery practice in Nigeria. The setback been suffered by cosmetic surgery in Nigeria has persisted despite having passed a decade since the media blow following the death of the wife of a sitting president during a cosmetic surgical procedure (Agbo, 2018). The eventual discouraging effect on the plastic surgery community has also persisted. The need for the way forward informs the decision to ascertain and review the attitude and the level of practice of cosmetic surgery among Nigerian plastic surgeons practicing in the country. Our findings reveal that though the plastic surgeons show faith in the Nigerian healthcare project, they still have to contend with media image wound, deformed client perception, and poor institutional support to be able to establish a trending cosmetic surgical practice in the Nigeria. There is a need also to establish a cosmetic surgeons' society in the country to help drive the campaign.

\subsection{Limitations of the Study}

We had a few limitations in this study which included the nonexistence of a cosmetic surgical society for possible databases and the unwillingness of some surgeons present in the conference to fully participate in the study. The respondents were not specifically required to state whether the reconstructive burden affected their attitude toward further training in aesthetic surgery leaving us to mere inference. The effect of the cost of training was not studied which could have contributed to considering the economic constraints in developing countries. We surveyed only the plastic surgeons on their perspective of cosmetic surgery and their views about the patient's believes without the patients/client's perspective. Their number though small but representative of the total number of plastic surgeons in Nigeria. Their opinion does not replace the public opinion of cosmetic surgery which still needs further exploration. 


\section{Conclusion}

The attitude of the plastic surgeons to cosmetic surgery is influenced by the attitude of the patients who show low acceptance of the cosmetic procedures mainly due to the wrong perception, and as such do not access the available treatment packages in the country. In other to reverse this, it is necessary to institute attitude-changing programs in addition to providing morale-boosting institutional support for the plastic surgeons. There is a need also for certification bodies to emphasize the cosmetic surgery component of the fellowship training. The establishment of an association for peer review practice would go a long way to giving the needed boost.

\section{Acknowledgments}

None

\section{Financial Disclosure and Product}

None of the authors has a financial interest in any of the products, devices, or drugs mentioned in this manuscript.

No funding was received for this article.

\section{Competing Interests Statement}

The authors declare that there are no competing or potential conflicts of interest.

\section{References}

Abubakar, A., Jamda, M., Ibrahim, A., Ajani, A., Iyun, K., \& Opara, K. (2016). University students and cosmetic surgery in Nigeria: A survey of perception, attitudes, and experiences. Nigerian Journal of Plastic Surgery, 12(1), 12. https://doi.org/10.4103/0794-9316.193733

Adedeji, O. A., Oseni, G. O., \& Olaitan, P. B. (2014). Awareness and Attitude of Healthcare Workers to Cosmetic Surgery in Osogbo, Nigeria. Surgery Research and Practice, 2014, 1-8. https://doi.org/10.1155/2014/869567

Agbo, N. (2018, October 30). The Rise of Cosmetic Surgery in Nigeria $\mid$ The Guardian Nigeria News - Nigeria and World NewsGuardian Life — The Guardian Nigeria News - Nigeria and World News. https://guardian.ng/life/the-rise-of-cosmetic-surgery-in-nigeria/

American Society of Plastic Surgeons. (2019a). Plastic Surgery Statistics Report 2019. https://www.plasticsurgery.org/documents/News/Statistics/2019/plastic-surgery-statistics-full-report-2019.p df

American Society of Plastic Surgeons. (2019b, March 11). New Plastic Surgery Statistics Reveal Trends Toward Body Enhancement|ASPS. Press Release. https://www.plasticsurgery.org/news/press-releases/new-plastic-surgery-statistics-reveal-trends-toward-bod y-enhancement

Blasier, R. B. (2009). The problem of the aging surgeon: When surgeon age becomes a surgical risk factor. Clinical Orthopaedics and Related Research, 467(2), 402-411. https://doi.org/10.1007/s11999-008-0587-7

Bradbury, E., \& Habel, A. (2009). Psychological and Social Aspects of CL/P in the Developing World, Including Implications of Late Surgery or No Surgery. In Management of Cleft Lip and Palate in the Developing World (pp. 159-170). John Wiley \& Sons Ltd. https://doi.org/10.1002/9780470988244.ch13

Freshwater, M. F. (2016). Giving thanks - Addressing the worldwide plastic surgeon shortage. Journal of Plastic, Reconstructive \& Aesthetic Surgery, 69(4), 443-445. https://doi.org/10.1016/J.BJPS.2015.12.002

Hidalgo, D. A., \& Sinno, S. (2016). Current Trends and Controversies in Breast Augmentation. Plastic and Reconstructive Surgery, 137(4), 1142-1150. https://doi.org/10.1097/01.prs.0000481110.31939.e4

Ibrahim, A. (2014). Sub-specialization in plastic surgery in sub-Saharan Africa: capacities, gaps and opportunities. The Pan African Medical Journal, 19, 13. https://doi.org/10.11604/pamj.2014.19.13.4190

Morait, S. R., Abuhaimed, M., Alharbi, M., Almohsen, B., Alturki, A., \& Alarbash, A. (2019). Attitudes and acceptance of the Saudi population toward cosmetic surgeries in Riyadh, Saudi Arabia. Journal of Family Medicine and Primary Care, 8(5), 1685. https://doi.org/10.4103/jfmpc.jfmpc_249_19

Nigerian Bureau of Statistics. (2017). 2017 Demographic Statistics Bulletin. Retrieved from https://nigerianstat.gov.ng/download/775

Nnadozie, U. U., Okorie, G. M., Maduba, C. C., Omoke, N. I., Ugbala, A., Uchendu, E., \& Ugwu, C. N. (2020). Abdominoplasty for male truncal obesity: Case report. Pan African Medical Journal, 36, 1-7. 
https://doi.org/10.11604/PAMJ.2020.36.52.19905

Olawoye, O. (2019). Building capacity for aesthetic surgery in Nigeria: perspectives from the cosmetic surgery fellowship at the Ivo Pitanguy Institute Rio de Janeiro, Brazil. Nigerian Journal of Plastic Surgery, 15(1), 14. https://doi.org/10.4103/njps.njps_1_19

Onah, I., Nnadozie, U., \& Ogbonnaya, I. (2010). Aesthetic surgery indications at the National Orthopaedic Hospital, Enugu. Nigerian Journal of Plastic Surgery, 6(1). https://doi.org/10.4314/njpsur.v6i1.53588

Papadopulos, N. A., Meier, A. C., Henrich, G., Herschbach, P., Kovacs, L., Machens, H. G., \& Klöppel, M. (2019). Aesthetic abdominoplasty has a positive impact on quality of life prospectively. Journal of Plastic, Reconstructive and Aesthetic Surgery, 72(5), 813-820. https://doi.org/10.1016/j.bjps.2018.12.020

Sarwer, D. B., Cash, T. F., Magee, L., Williams, E. F., Thompson, J. K., Roehrig, M., ... \& Romanofski, M. (2005). Female college students and cosmetic surgery: An investigation of experiences, attitudes, and body image. In Plastic and Reconstructive Surgery (Vol. 115, Issue 3, pp. 931-938). Plast Reconstr Surg. https://doi.org/10.1097/01.PRS.0000153204.37065.D3

Swami, V., Chamorro-Premuzic, T., Bridges, S., \& Furnham, A. (2009). Acceptance of cosmetic surgery: Personality and individual difference predictors. Body Image, 6(1), 7-13. https://doi.org/10.1016/j.bodyim.2008.09.004

\section{Copyrights}

Copyright for this article is retained by the author(s), with first publication rights granted to the journal.

This is an open-access article distributed under the terms and conditions of the Creative Commons Attribution license (http://creativecommons.org/licenses/by/4.0/). 